American Journal of Animal and Veterinary Sciences 6 (2): 73-76, 2011

ISSN 1557-4555

(C) 2011 K. Mirhadi, This open access article is distributed under a Creative Commons Attribution

(CC-BY) 3.0 license

\title{
Effect of Nifedipine on Dichlorvos-Induced Seizure in Mice
}

\author{
Khayatnouri Mirhadi \\ Department of Pharmacology, \\ Tabriz Branch, Islamic Azad University, Tabriz, Iran
}

\begin{abstract}
Problem statement: Dichlorvos a synthetic organophosphate poisons is the property of insecticide. These toxins as insecticides in agriculture and medicine for animals and the destruction of ectoparasites can be used. Studies have shown that Dichlorvos creation seizure effects in different animals. Nifedipine, dihydropyridine calcium channel blockers, widely used for treatment of cardiovascular diseases. Studies have shown that the calcium channel blockers are anticonvulsant effects in different animal models. The aim of this study was to determine the effect of nifedipine on Dichlorvosinduced seizures in mice. Approach: In this experiment, the animals were received different doses of nifedipine $\left(2.5,5,10,20\right.$ and $\left.40 \mathrm{mg} \mathrm{kg}^{-1}\right)$ intraperitoneally $30 \mathrm{~min}$ before intraperitoneal injection of Dichlorvos $\left(50 \mathrm{mg} \mathrm{kg}^{-1}\right)$. After Dichlorvos injection, clonic and tonic seizures and death was investigated. Results: Results showed that nifedipine dose dependently reduced the severity of Dichlorvos-induced seizures, so that nifedipine dose 10 and $40 \mathrm{mg} \mathrm{kg}^{-1}$, respectively, the lowest $(\mathrm{p}<0.05)$ and highest $(\mathrm{p}<0.001)$ had anticonvulsant effects. Conclusion: The anticonvulsant activity of nifedipine suggests that possibly due to antagonistic effect on voltage-dependent calcium channel.
\end{abstract}

Key words: Dichlorvos-induced seizure, nifedipine dose, vice versa, anticonvulsant effects, cellular calcium, neuronal function, nerve tissue, epileptic animal, intracellular calcium, penicillininduced seizures

\section{INTRODUCTION}

Epilepsy is one of the major neurological diseases in humans and about one percent of the population is involved. It has been shown that epileptic seizure occurs due to occasional discharges in nerve tissue. It is recognized that occasional changes in reversible neuronal function, causing brain electrical activity. In some cases, the seizure occurs due to the entry of calcium ions into nerve cells and reducing intracellular calcium concentration in some epileptic animal models has inhibitory effect on seizures. During seizures increased intracellular calcium ion concentration and but extra cellular calcium concentration decreases (Khanna et al., 2000; Van Luijtelaar et al., 1995). Calcium channel antagonists for the treatment of hypertension were produced in the year 1980. Use of these drugs over time to treat other diseases was developed, such as treatment of angina, supraventricular tachycardia attack, hypertrophic cardiomyopathy, pulmonary hypertension and migraine. Recently have shown that calcium channel blockers may have anticonvulsant effects in some animal models. Calcium channel blockers inhibit calcium ion flow through L-type calcium channels sensitive to voltage (Kulak et al., 2004). It has been shown that calcium channel inhibitors in models of nerve tissue in a large protective effect (Mikati et al., 2004). Have also reported that calcium channel inhibitors on the anticonvulsant effects of some models have (Chakrabarti et al., 1998; Marinho et al., 1997), but in all animal models of seizures has not demonstrated these effects (Gasior et al., 1996; Khosla and Pandhi, 2000). Also in rats anticonvulsant effects of calcium channel inhibitors shown but seizure agent has not Dichlorvos. Some medications such as anticonvulsants phenytoin and carbamazepine effect by inhibiting sodium channels directly and indirectly by preventing the flow of calcium from the membranes of neurons and reduction of excessive concentration of intracellular calcium. Specific drugs used to treat epilepsy are absence seizure kind of like channels as T-type calcium in thalamic neurons are blocked. This reduced calcium ion concentration of the important goals in development is neuroprotective and antiepileptic drugs (Kulak et al., 2004; Van Luijtelaar et al., 1995). Calcium entry into neurons play an important role in creating the seizures and calcium channel inhibitors have different effects on 
health, including cardiovascular diseases, migraine and headaches caused by vascular changes, nerve regeneration and neuronal regenerative processes (Khanna et al., 2000), So it seems calcium channel inhibitors used to treat seizures can be useful. Results of these studies for the anticonvulsant effects of calcium channel inhibitors suggests, therefore likely to nifedipine reduce Dichlorvos-induced seizures. Since no research based on the combined effect of these seizures from Dichlorvos there, in this case study seems necessary. Insecticide use in agriculture and veterinary medicine as strange since World War II and grew during the past 20 years has reached its highest rate constant. While the main consumers of agricultural insecticide industry is also large quantities of other industries use them and their applications in and around homes is considerable. Most of insecticide residues on the remaining products and people exposed to low doses of chemicals through the foods. Numerous incidents of acute insecticide poisoning caused by eating food that mainly followed during storage or transportation had been infected was created (Goodman et al., 2001). Including the insecticide, which are potential toxicity, are organophosphate. One of the organophosphate is Dichlorvos. The aim of this study was to determine the effect of nifedipine (calcium channel antagonist) on Dichlorvos-induced seizures.

\section{MATERIALS AND METHODS}

Male mice NMRI, weighing between 25-30 g and maintenance of laboratory animals breeding center of Tabriz Islamic Azad University purchased and were kept in room temperature, light and humidity constant. Animals' access to food and water were freely. All tests were performed between 10-16 h. Dichlorvos and nifedipine, both were solved in Twin 80 (5\%). Animals were divided randomly and placed in treatment groups (each group $\mathrm{n}=10$ ). Nifedipine and Twin 80 were administered intraperitoneally with constant volume and by weight per animal. To remove the effect of injection volume on seizures, all drugs and Twin 80, at $10 \mathrm{~mL} \mathrm{~kg}^{-1}$ was set. First, seizures was assessed in animals receiving Dichlorvos and then evaluated the effect of Twin 80 on Dichlorvos-induced seizures with the above injection, $30 \mathrm{~min}$ before the seizure was determined. More experimental animals, different doses of nifedipine $\left(2.5,5,10,20\right.$ and $\left.40 \mathrm{mg} \mathrm{kg}^{-1}\right)$ received $30 \mathrm{~min}$ before the intraperitoneal injection of Dichlorvos. To create seizures, mice received Dichlorvos $\left(50 \mathrm{mg} \mathrm{kg}^{-1}\right)$ intraperitoneally and then the animals treated for $120 \mathrm{~min}$ were recorded by video camera. Films from the following four behaviors were recorded: starting time of clonic seizures after injection of Dichlorvos (second), Generation time of death after Dichlorvos injection (second), mortality after injection of Dichlorvos (persentage) and type of seizures induced by injection of Dichlorvos (percentage). After testing data as the mean \pm SEM expression and to analyze data, ANOVA followed by Tukey multiple comparison tests were used. Value of $p<0.05$ to determine significance between groups was considered.

\section{RESULTS}

Effect of Twin 80 as solvent, on Dichlorvos-induced seizures showed that this substance has no significant effect on seizures. Therefore the results had not presented in graphs and tables have been avoided. Effect of different doses of nifedipine $(2.5,5,10,20$ and $40 \mathrm{mg}$ $\mathrm{kg}$ ) on Dichlorvos-induced seizures showed that this drug dose-dependently reduced the Dichlorvos-induced seizures (Fig. 1 and 2) Most anticonvulsant effect of nifedipine on the mortality and severity of seizures with a dose of $40 \mathrm{mg} \mathrm{kg}^{-1}$ was observed (Fig. 3 and Table 1).

Table 1: Effect of different doses of nifedipine on the type of seizures induced by Dichlorvos injection (\%)

\begin{tabular}{lccr}
\hline Type of seizures (\%) & Low & Moderate & Severe \\
Group & 0 & 0 & 100 \\
\hline Dichlorvos & 0 & 0 & 100 \\
Nifedipine 2.5 + Dichlorvos & 0 & 20 & 80 \\
Nifedipine 5 + Dichlorvos & 10 & 40 & 50 \\
Nifedipine 10 + Dichlorvos & 20 & 40 & 40 \\
Nifedipine 20 + Dichlorvos & 30 & 60 & 10 \\
Nifedipine 40 + Dichlorvos & & &
\end{tabular}

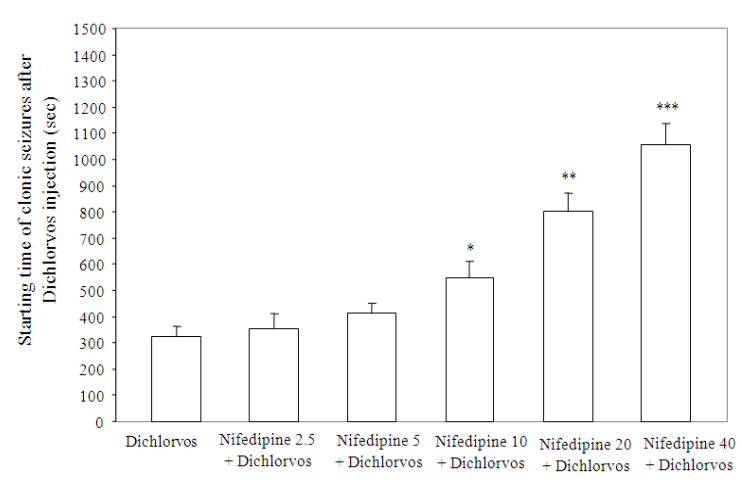

Fig. 1:Effect of different doses of nifedipine on the starting time of clonic seizures after injection of Dichlorvos (sec). Mean \pm SEM any form of graphs are presented. $* \mathrm{p}<0.05$, $* * \mathrm{p}<0.01$ and $* * * \mathrm{p}<0.001$ compared with Dichlorvos group 


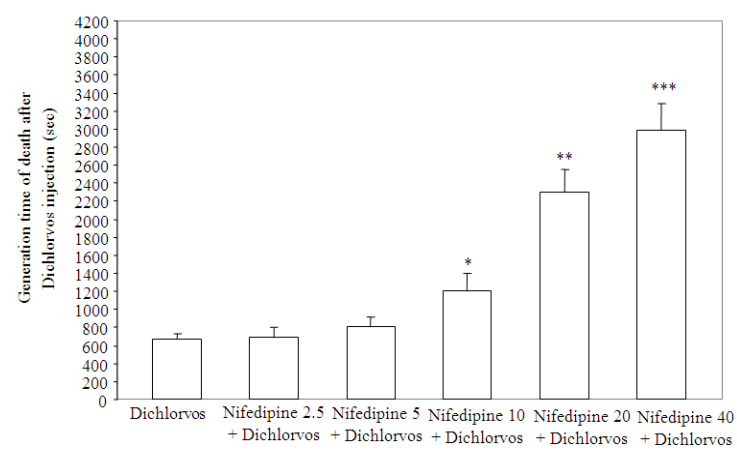

Fig. 2: Effect of different doses of nifedipine on Generation time of death after Dichlorvos injection (second). Mean \pm SEM any form of graphs is presented. $* \mathrm{p}<0.05, * * \mathrm{p}<0.01$ and $* * * \mathrm{p}<0.001$ compared with Dichlorvos group

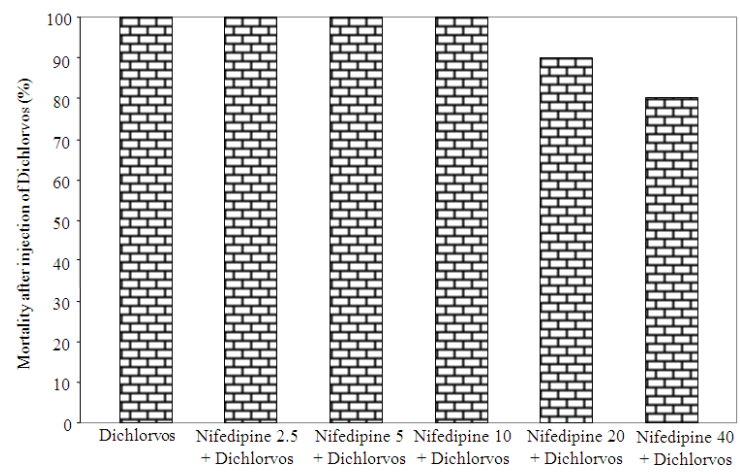

Fig. 3: Effect of different doses of nifedipine on the mortality after injection of Dichlorvos (\%)

\section{DISCUSSION}

In this study, Dicholorvos cause clonic and tonic seizures and ultimately death. After the mice received intraperitoneal dichlorvos, some degree of tremor and excessive activity showed that over time the symptoms became more severe and cause death. In this study, nifedipine dose dependently reduced clonic and tonic seizures and deaths from Dicholorvos. The results showed that the results of different researchers before treatment with calcium channel antagonists, seizure activity creation of different materials down to is in agreement. If nimodipine in preventing tonic convulsions caused by PTZ (Khanna et al., 2000), Aminophyline (Chakrabarti et al., 1998) and pilocarpine (Marinho et al., 1997) have a protective effect, but unlike the above models in all tests anticonvulsant effect has been observed. For example Kainic acid induced seizures, administration of nimodipine before this material could not reduce seizures (Mikati et al., 2004). In another study showed that nimodipine with values above $80 \mathrm{mg} \mathrm{kg}^{-1}$ could inhibit tonic seizures from chemicals including PTZ in mice and rats (Gasior et al., 1996; Wurpel and Iyer, 1994), but later showed that high doses of calcium channels blockers cause systemic and cardiac disorders, such as a sharp reduction in coronary blood pressure, decreased movements, imbalance and headache relief (Kulak et al., 2004; Van Luijtelaar et al., 1995). Epilepsy in patients who were resistant to treatment, have reported that nimodipine in an uncontrolled study, seizure frequency is reduced (De Falco et al., 1992), but in another study that two strains were unaware controls, no anticonvulsant effects was observed by nimodipine (Larkin et al., 1991). Other problems prescription drug, long-term administration of drugs with low prescribed intervals (three to four times a day to several weeks) and side effects include headache and hypotension, pronounced the man was from animal models. However, after 24 and $72 \mathrm{~h}$ of administration of nimodipine, percent of alpha and theta waves was increased and vice versa percent in delta waves electroencephalogram was reduced (Kulak et al., 2004; Larkin et al., 1991). Other studies have shown that the anticonvulsant effects of calcium channel blockers, especially nimodipine with other antiepileptic drugs, increases. For example, in mice and rats with concurrent administration of nimodipine with other drugs can be decreased PTZ-induced tonic seizures, seizures resulting from sound and relieve the electroshock (Gasior et al., 1996; Khosla and Pandhi, 2000; Mikati et al., 2004). Dihydropyridine calcium channels blockers in experimental seizures by ischemia, bicuculine, electrical cortical shocks, nitrous oxide and alcohol withdrawal syndrome is caused due, have anticonvulsant effects. In another study, calcium channel blockers such as verapamil, nifedipine and Flunarizine to prevent of penicillin-induced seizures and electroencephalogram range have changed (Kriz et al., 2003). Calcium channel inhibitors on seizures induced by N-Methyl-D, L-Aspartate (NMDLA) and dihydropyridine calcium channel agonist BAY K 8644 have been effective (Palmer et al., 1993; Van Luijtelaar et al., 1995). In another study on rats have shown that nimodipine in animal models of seizures, nerve discharge from BAY K 8644 and reduced the decrease in spike-wave EEG (Van Luijtelaar et al., 1995). Also have shown that this drug is ischemic brain damage has protective effects (Kriz et al., 2003). These studies suggest that protective effects of calcium channel antagonists probably due to blocking L-type calcium channels during seizures. 
These drugs inhibit voltage-dependent calcium channels in seizures, the increase in intracellular calcium to prevent. Well marked that increased $\mathrm{Ca}^{2+}$ into the cell in the incidence of certain types of seizures plays a role (Khanna et al., 2000), also marked the loss of calcium outside the cell with reduced flow of calcium from the membranes of neurons for several seconds the discharge of neurons that causes seizures be prevented and the threshold increases (Mc Namara, 1992). Some of the other antiepileptic drugs such as phenytoin and carbamazepine with a direct effect on neuronal sodium channels act directly or indirectly the flow of calcium ions from the membranes of neurons are inhibited (Kulak et al., 2004; Van Luijtelaar et al., 1995). So it is likely that dihydropyridine calcium channel antagonists to act with similar mechanisms. Also have shown that nimodipine may inhibit calcium, sodium, chloride, potassium and calcium-dependent glutamate channels (Van Luijtelaar et al., 1995).

\section{CONCLUSION}

In summary, this study showed that nifedipine (voltage-dependent calcium channel antagonist type L) decreased clonic and tonic seizures from Dichlorvos in mice is probably the main mechanism anticonvulsant related to block calcium channels and reduce calcium flow with in neurons. Of course, that this could be generalized to humans rather than question and anticonvulsant effects of dihydropyridine calcium channel antagonists in humans, further investigation is needed.

\section{REFERENCES}

Chakrabarti, A., H. Kaur Saini and S.K. Garg, 1998. Dose-finding study with nimodipine: A selective central nervous system calcium channel blockers on aminophylline induced seizure model in rats. Brian Res. Bull, 45: 495-499. PMID: 9570719

De Falco, F.A., U. Bartiromo, L. Majello, G. Di Geronimo and P. Mundo, 1992. Calcium antagonist nimodipine in intractable epilepsy. Epilepsia, 33: 343-345. PMID: 1547764

Gasior, M., R. Kaminski, T. Burdniak, Z. Kleinrok and S.J. Czuczwar, 1996. Influence of nicardipine, nimodipine and flunarizine on the anticonvulsant efficacy of antiepileptics against pentylenetetrazol in mice. J. Neural Transm. Gen. Sect., 103: 819831. PMID: 8872866

Goodman, L.S., L.E. Limbird, J.G. Hardman and A.G. Gilman, 2001. Goodman and Gilman's the Pharmacological Basis of Therapeutics. 10th
Edn., Mc Graw-Hill, New York, USA., ISBN: 9780071354691, pp: 2148.

Khanna, N., S. Bhalla, V. Verma and K.K. Sharma, 2000. Modulatory effects of nifedipine and nimodipine in experimental convulsions. Ind. J. Pharmacol., 32: 347-352. DOI: medind.nic.in/ibi/t00/i6/ibit00i6p347

Khosla, P. and P. Pandhi, 2000. Anticonvulsant effect of nimodipine alone and in combination with diazepam and phenytion in a mouse model of status epilepticus. Methods Find Exp. Clin Pharmacol., 22: 731-736. PMID: 11346893

Kriz, J., G. Zupan and A. Simonic, 2003. Differential effects of dihydropyridine calcium channel blockers in kainic acid-induced experimental seizures in rats. Epilepsy Res., 52: 215-225. PMID: 12536054

Kulak, W., W. Sobaniec, K. Wojtal and S.J. Czuczwar, 2004. Calcium modulation in epilepsy. Pol. J. Pharmacol., 56: 29-41. PMID: 15047975

Larkin, J.G., P.J. McKee, J. Blacklaw, G.G. Thompson and I.C. Morgan et al., 1991. Nimodipine in refractory epilepsy: A placebo-controlled, add-on study. Epilepsy Res., 9: 71-77. PMID: 1909241

Marinho, M.M., V.M. De Bruin, F.C. De Sousa, L.M. Aguiar and R.S. De Pinho et al., 1997. Inhibitory action of a calcium channel blocker (nimodipine) on seizure and brain damage induced by pilocarpine and lithium-pilocarpine in rats. Neurosci Lett., 235: 13-16. PMID: 9389584

Mc Namara, J.O., 1992. The neurobiological basis of epilepsy. Trends Neurosci., 15: 357-359. PMID: 1279853

Mikati, M.A., G.L. Holmes, S. Werner, N. Bakker and L. Carmant et al., 2004. Effects of nimodipine on the behavioral sequalae of experimental status epilepticus in prepubescent rats. Epilepsy Behav., 5: 168-174. PMID: 15123017

Palmer, G.C., M.L. Stagnitto, R.K. Ray, M.A. Knowels and R. Harvey et al., 1993. Anticonvulsant properties of calcium channel blockers in mice: NMDLA and BAYK 8644-induced convulsions are potently blocked by the dihydropyridines. Epilepsia, 34: 372-380. PMID: 7681002

Van Luijtelaar, E.L.J.M., N. Ales and A.M.L. Coenen, 1995. Role of L-type calcium channel modulation in nonconvulsive epilepsy in rats. Epilepsia, 36: 86-92. PMID: 7528137

Wurpel, J.N. and S. Iyer, 1994. Calcium channel blockers verapamil and nimodipine inhibit kindling in adult and immature rats. Epilepsia, 35: 443-449. PMID: 8156971 